\title{
Reduction of arrhythmias in primary hyperparathyroidism, by parathyroidectomy, evaluated with 24-h ECG monitoring
}

\author{
Jessica Pepe, Cristiana Cipriani, Mario Curione, Federica Biamonte, \\ Luciano Colangelo, Vittoria Danese, Veronica Cecchetti, Chiara Sonato, \\ Federica Ferrone, Mirella Cilli and Salvatore Minisola \\ Department of Internal Medicine and Medical Disciplines, 'Sapienza' University of Rome, Rome, Italy
}

Correspondence should be addressed to J Pepe

Email

jessica.pepe@uniroma1.it

\begin{abstract}
Objective: Hypercalcemia may induce arrhythmias. There are no data on the prevalence of arrhythmias in primary hyperparathyroidism (PHPT) in daily life. Aim of the study was to investigate both the prevalence of arrhythmias in patients with PHPT compared to controls and the impact of parathyroidectomy, evaluated by 24-h electrocardiogram (ECG) monitoring.

Design: This is a randomized study.

Methods: Twenty-six postmenopausal women with PHPT and 26 controls were enrolled. PHPT patients were randomized to two groups: 13 underwent parathyroidectomy (Group A) and 13 were followed up conservatively (Group B). After 6 months, patients were studied again. Each patient underwent mineral metabolism biochemical evaluation, bone mineral density measurement, standard ECG and 24-h ECG monitoring.

Results: PHPT patients showed higher calcium and parathyroid hormone compared to controls and a higher prevalence of both supraventricular (SVBPs) and ventricular premature beats (VPBs) during 24-h ECG monitoring. Groups A and B showed no differences in mean baseline biochemical values and ECG parameters. Mean value of QTC in PHPT groups was in the normal range at baseline, but significantly shorter than controls. A negative correlation was found between QTc and ionized calcium levels $(r=-0.48, P<0.05)$. After parathyroidectomy, Group A had a significant reduction in SVPBs and VPBs compared to baseline and restored normal QTc. Group B showed no significant changes after a 6-month period.
\end{abstract}

Conclusions: The increased prevalence of SVPBs and VPBs is significantly reduced by parathyroidectomy, and it is mainly related to the short QTC caused by hypercalcemia.

\section{Introduction}

Recently, there has been growing interest regarding arrhythmias in patients with primary hyperparathyroidism (PHPT); these can be considered as a non-classical manifestation of the disease, which is characterized by hypercalcemia and elevated or non-suppressed parathyroid hormone levels (PTH) $(1,2)$. Indeed, hypercalcemia modifies the cardiac myocyte repolarization, which is represented in the electrocardiogram (ECG) by a
European Journal of Endocrinology

(2018) 179, 117-124 shortening of the QT interval, a well-known risk factor for arrhythmias (3).

The exact prevalence of short QT interval in PHPT and more importantly of arrhythmias is unknown, because the ECG is not performed on a routine basis in this population to ascertain QT length, even if an ECG is routinely performed in PHPT patients before surgery. Indeed, cardiovascular assessment is not recommended

Published by Bioscientifica Ltd. 
in the current guidelines on the management of PHPT patients, mainly due to the lack of randomized studies on this aspect (4). The current guidelines focus only on traditional aspects of the disease, such as skeletal and renal involvement (4).

So far, short QT interval has been demonstrated by some authors in PHPT patients $(5,6)$; interestingly, during an exercise test, which is an experimental method that physiologically induces a further shortening of QT, an increased incidence of ventricular premature beats (VPBs) was described (7). We have also demonstrated that the increased incidence of VPBs was predicted by serum calcium level during peak exercise (8) and that parathyroidectomy (PTx), in a randomized trial, significantly reduced VPBs and restored physiological QT dynamics (9).

It would be of interest to know the prevalence of arrhythmias during the activities of daily life in PHPT patients, without an induction of a shortening of QT by experimental conditions, and the effect of PTx on this aspect. Knowledge regarding the prevalence of arrhythmias may shed new light on the cardiovascular and mortality risks in this population, which is still a debatable issue with conflicting results reported in the literature (10). The difficulty in ascertaining the prevalence of arrhythmias arises from that fact that benign arrhythmias are generally asymptomatic lasting only a few seconds. Thus, the aim of this study was to investigate the prevalence of arrhythmias in patients affected by PHPT compared to controls by 24-h ECG monitoring; the effect of PTx was also investigated.

\section{Methods}

\section{Subjects}

Thirty-three consecutive Caucasian postmenopausal women (age range 45-80 years) diagnosed for the first time as having PHPT at the Metabolic Bone Disease Unit of the University of Rome 'Sapienza' (Italy), between January 2015 and July 2016, were enrolled. The diagnosis of PHPT was made following the finding of hypercalcemia with an inappropriately high plasma level of PTH (11). During the same period, in the same center, a control group of volunteers was enrolled from women visiting the center for an osteoporosis screening. The group was recruited consecutively and consisted of 26 healthy, Caucasian, postmenopausal women within the same age range. They all live in the same area; therefore, it is very likely that they all have similar lifestyles. Exclusion criteria were as follows: left bundle branch block, pre-excitation and presence of pacemaker, history of severe valvular disease, hypertrophic cardiomyopathy, a Sokolow-Lyon index higher than $3.5 \mathrm{mV}$, which has been defined a threshold to diagnose left ventricular hypertrophy (12). Sokolow-Lyon index is derived by ECG, defined as the sum of $S$ wave voltage in lead $V_{1}$ plus the larger of the $R$ wave voltage in lead V5 or V6 (12). None of the patients enrolled were treated with drugs that could interfere with the QT interval. Other exclusion criteria were known coronary artery disease, diabetes mellitus types 1 and type 2 , hypothyroidism and hyperthyroidism, history of hypohyperkalemia, hypo-hypomagnesaemia, renal disease with a serum creatinine higher than $1.35 \mathrm{mg} / \mathrm{dL}$ and BMI $>30 \mathrm{~kg} / \mathrm{m}^{2}$, caffeine intake higher than $80 \mathrm{mg}$, which is approximately two Italian coffees per day. The study was approved by our institutional review board (Department of Internal Medicine and Medical Disciplines) and then by local ethics committee ('Policlinico Umberto I').

All patients gave written informed consent. After informed consent was obtained, patients and control subjects with $25(\mathrm{OH})$ vitamin D levels $<20 \mathrm{ng} / \mathrm{mL}$ were treated with 50 000IU weekly of cholecalciferol for 1 month; calcium supplements (1000 mg p.o. daily) were given to those on a calcium-poor diet after completing a validated questionnaire (13). From a biochemical point of view, both PHPT patients and control subjects were studied after 1 month of such a calcium and vitamin $\mathrm{D}$ regimen. Following initial assessment, one patient affected by PHPT was excluded due to the presence of diabetes mellitus type 2 and a BMI $>30 \mathrm{~kg} / \mathrm{m}^{2}$, and two PHPT patients were excluded for uninterpretable ECG. The remaining 30 patients were randomized to either PTx within 15 days or conservative management for 6 months prior surgery; randomization was performed using a computer-generated numbers and blocks comprised 15 patients each. However, four patients (two in each group) did not accept this randomization strategy because they wanted to have immediate neck exploration; therefore, they abandoned the study. Six months following the initial evaluation, both groups of patients, those who were randomized to surgery and those who were followed conservatively, underwent the same biochemical evaluations and cardiovascular procedures.

\section{Cardiovascular risk factors}

We considered the following cardiovascular risk factors: hypertension, dyslipidemia, alcohol consumption (more 
than three alcohol units per day) and current smoking status (more than five cigarettes per day), assessed in a face-to-face medical interview. Blood pressure (millimetres of mercury) was measured after $5 \mathrm{~min}$ of rest at the upper left arm with subjects in a lying position, using an oscillometric blood pressure (BP) monitor.

The diagnosis of dyslipidemia was made on the basis of anamnestic data, because we did not measure the cholesterol level.

\section{Biochemical evaluation}

Mineral metabolism was evaluated by measuring total and ionized calcium, phosphorus, creatinine, $25(\mathrm{OH})$ vitamin D, PTH, 24-h urinary calcium and alkaline phosphatase as described previously $(14,15)$. Thyrotropin (TSH) was measured using radioimmunoassay (IRMA TSH-US, Irma ct, Radim Diagnostic, Pomezia, Italy) (16).

Bone mineral density (BMD) of the lumbar spine (L1-L4) in the anterior-posterior projection, of the femur (neck and total hip) and nondominant distal one-third radius was measured in each patient by dual-energy X-ray absorptiometry (Hologic QDR 4500, Hologic Inc, Waltham, MA, USA). The precision error of lumbar spine and total hip measurements was 1.3 and $1.7 \%$ respectively and $1.3 \%$ at the distal $1 / 3$ radius (17). Fractured lumbar vertebrae were excluded from BMD measurement.

Each patient and control subject underwent standardized lateral radiographs of the thoracic and lumbar spine, centered at T8 and L3 respectively, at a film focus distance of $105 \mathrm{~cm}$. Vertebral deformity was defined according to Genant's method (18). All patients had abdominal ultrasound performed by a skilled radiologist to detect renal calculi. Each ultrasonogram was performed with a low-medium frequency $(3.5-5 \mathrm{MHz}$, depending on the physical characteristics of the subject) convex probe and the ultrasound scanner (Esaote MyLab 70 x Vision; Genoa, Italy), as previously described (19).

\section{Electrocardiography}

Standard 12-lead ECG was recorded in subjects enrolled. QT intervals were adjusted using Bazett correction formula $(\mathrm{QTc}=\mathrm{QT} / \sqrt{\mathrm{RR}})$ (20). Participants underwent 24-h ECG monitoring to detect rhythm disturbances; with a 3-channels standard device (DR200/HE, NorthEast Monitoring). Artifacts in the electronic recordings were eliminated after having been reviewed by the cardiologist of our group (MC).

\section{Statistical analysis}

Statistical analysis was performed using SPSS for Windows version 13 (SPSS Inc.). Categorical variables are described with numbers and percentages. Continuous variables are expressed as mean value \pm S.D. Differences between groups were assessed with chi-squared test for categorical variables, and comparison of continuous variables was made using unpaired and paired $t$-test. Correlations between QTc and biochemical parameters were assessed using linear regression. A $P$ value $<0.05$ was considered statistically significant. Since the main outcome of the study was to monitor arrhythmias before and after parathyroidectomy and there are no data on the prevalence of arrhythmias in PHPT patients, it was not possible to calculate a sample size. However, we previously performed a study on the incidence of arrhythmias during a stress test observing a decrease in a sample of 12 PHPT patients, together with a reduction of QTc (9). Thus, we enrolled at least 12 PHPT patients also considering loss in follow-up and the double of controls, as we did in our previous study (9).

\section{Results}

Each PHPT patient met current indications for surgery: osteoporosis was diagnosed in $54.1 \%$ of patients, kidney stones in $33.3 \%$ and $19 \%$ had total calcium level $1 \mathrm{mg} /$ $\mathrm{dL}$ above the upper limit of the normal range. There were no differences concerning traditional cardiovascular risk factors between patients and controls. Hypertension was diagnosed in 50\% of PHPT patients and in 33.3\% of controls, dyslipidemia in $20.8 \%$ and $16.6 \%$ respectively $(P=n s)$. Hypertensive subjects taking pharmacological therapy were $39 \%$ in the PHPT group and $62.5 \%$ in the controls $(P=\mathrm{ns})$, while those without therapy were $61 \%$ and $37.5 \%$ respectively $(P=\mathrm{ns})$. Among those treated for hypertension, we found no differences regarding the class of drugs prescribed. In particular, alpha-blockers drugs were prescribed in $24 \%$ of hypertensive PHPT patients and $50 \%$ of hypertensive controls ( $P=\mathrm{ns})$, ace inhibitors in $15 \%$ of hypertensive PHPT patients and $12.5 \%$ of hypertensive controls $(P=n s)$. We found no differences regarding the percentage of PHPT patients taking statins compared to controls ( $66.6 \%$ vs $50 \%, P=$ ns), while the remaining dyslipidemic patients adhered to a fat-restrictive diet. Alcohol consumption was ascertained in $15.4 \%$ of PHPT population and $23 \%$ in control subjects $(P=n s)$. Tobacco use was recorded in $27 \%$ of PHPT population and 
$38.4 \%$ of control subjects $(P=\mathrm{ns})$. The above mentioned cardiovascular risk factors did not differ between Groups $\mathrm{A}$ and $\mathrm{B}$.

There was no significant difference either between PHPT patients and controls, or between Groups A and $\mathrm{B}$ concerning anthropometric variables (Table 1). As expected, there were significant differences when considering calcium-phosphorus metabolism in PHPT patients compared to controls. In particular, compared to controls, Groups A and B had increased and significantly different mean values of total and ionized calcium, 24-h urinary calcium, PTH and lower mean levels of phosphorus (Table 1). In particular, considering serum calcium levels, we found a mild elevation in patients of Group A not significantly different compared to patients of Group B (total calcium: $10.89 \pm 0.50 \mathrm{mg} / \mathrm{dL}$ vs $10.90 \pm 0.57$, $P=0.96)$. Both groups had mean values of total calcium significantly different compared to the control group $(9.42 \pm 0.35 \mathrm{mg} / \mathrm{dL}$, all $P<0.05)$ (Table 1). Patients of Groups A and B showed no differences considering the other biochemical parameters studied (Table 1).

The standard ECG parameters (Table 2) were within normal values and did not differ neither between the PHPT patients of Group A and B nor when compared to controls, except QTc interval. Mean value of QTc was in the normal range at baseline (Group A: 400.6 \pm 14.9 ; Group B: $399.0 \pm 14.7 \mathrm{~ms}, \quad P=0.78)$, but significantly shorter than controls $(411.9 \pm 17.2 \mathrm{~ms}, P<0.05)$ (Table 2$)$. QTc, in the PHPT group correlated negatively with serum ionized calcium level $(r=-0.48, P<0.05)$ (Fig. 1), but not with other parameters. A similar negative correlation between QTc and ionized calcium was found considering all samples studied including PHPT patients and controls $(r=-0.51, P<0.05)$ (Fig. 2).

No symptoms were reported by participants during the 24-h ECG monitoring and no major arrhythmias were found. The main findings were higher prevalence of premature beats, both supraventricular (SVPBs) and ventricular (VPBs), in PHPT patients compared to controls (Table 3). In particular, more than $30 \%$ of the patients in Groups A and B had SVPBs in triplets compared to none in the controls group (all $P<0.05$ ).

If we consider the absolute number of SVPBs, we found in both groups that one-third of sample experienced more than 76 SVPBs compared to $4 \%$ of the patients in the control group (all $P<0.05$ ) (Table 3 ). We chose the threshold of 76 SVPBs, because it has been shown to be the threshold that predicts mortality, in the general population (21). A significant higher prevalence of VPBs were found in Groups A and B compared to controls: almost $70 \%$ of patients in both groups had VPBs compared to $27 \%$ of the subjects in the control group (all $P<0.05$ ) (Table 3). We found no difference between Groups A and $B$ regarding prevalence of SVPBs and VPBs at baseline.

After 6 months, (mean follow-up time in days $180 \pm 15)$, patients who underwent parathyroidectomy (Group A) showed a significant reduction of mean total, ionized calcium and PTH levels compared to baseline (total calcium: $10.89 \pm 0.53$ vs $9.79 \pm 0.46 \mathrm{mg} /$ $\mathrm{dL}$, ionized calcium $1.42 \pm 0.13$ vs $1.26 \pm 0.02 \mathrm{mmol} / \mathrm{L}$, PTH $99.5 \pm 57.47$ vs $48.0 \pm 11.92 \mathrm{pg} / \mathrm{mL}$, respectively, all $P<0.01$ ). All patients who underwent surgery were successfully cured. These parameters remained stable in Group B. The ECG parameters and heart rate did not show

Table 1 Baseline anthropometric parameters and biochemical values in PHPT patients (Group A and Group B) and controls Results are presented as mean \pm 1 s.D.

\begin{tabular}{|c|c|c|c|c|c|c|}
\hline & \multicolumn{2}{|c|}{ PHPT } & \multirow[b]{2}{*}{ Controls $(n=26)$} & \multicolumn{3}{|c|}{$P$ values } \\
\hline & Group A $(n=13)$ & Group B $(n=13)$ & & Group A vs controls & Group B vs controls & Group A vs Group B \\
\hline Age (years) & $66.0 \pm 6.5$ & $70.6 \pm 8.4$ & $66.5 \pm 5.6$ & 0.80 & 0.07 & 0.13 \\
\hline Years since menopause & $9.7 \pm 6.0$ & $11.9 \pm 5.8$ & $10.1 \pm 4.9$ & 0.82 & 0.31 & 0.35 \\
\hline BMI $\left(\mathrm{kg} / \mathrm{m}^{2}\right)$ & $25.9 \pm 3.8$ & $25.0 \pm 3.3$ & $24.3 \pm 3.3$ & 0.18 & 0.53 & 0.52 \\
\hline Creatinine (mg/dL) & $0.8 \pm 0.2$ & $0.7 \pm 0.2$ & $0.8 \pm 0.1$ & 1 & 0.06 & 0.21 \\
\hline Calcium (mg/dL) & $10.9 \pm 0.5$ & $10.9 \pm 0.6$ & $9.4 \pm 0.3$ & $<0.0001$ & $<0.0001$ & 1 \\
\hline Ionized calcium (mmol/L) & $1.4 \pm 0.1$ & $1.4 \pm 0.0$ & $1.24 \pm 0.0$ & $<0.0001$ & $<0.0001$ & 1 \\
\hline Phosphorus (mg/dL) & $2.9 \pm 0.4$ & $3.1 \pm 0.4$ & $3.9 \pm 0.5$ & $<0.0001$ & $<0.0001$ & 0.21 \\
\hline 25(OH)D (nmol/L) & $32.2 \pm 11.0$ & $33.6 \pm 8.5$ & $33.3 \pm 18.5$ & 0.84 & 0.95 & 0.71 \\
\hline PTH (ng/L) & $97.8 \pm 55.4$ & $78.5 \pm 22.1$ & $45.6 \pm 7.5$ & $<0.0001$ & $<0.0001$ & 0.25 \\
\hline 24-h u-calcium (mg/24h) & $264.5 \pm 137.0$ & $233.3 \pm 100.8$ & $162.6 \pm 70.2$ & 0.003 & 0.01 & 0.51 \\
\hline Alkaline phosphatase (U/L) & $95.8 \pm 28.7$ & $92.1 \pm 45.3$ & $106.4 \pm 50.1$ & 0.48 & 0.39 & 0.80 \\
\hline TSH (mIU/L) & $1.3 \pm 0.5$ & $1.6 \pm 0.4$ & $1.5 \pm 1.1$ & 0.53 & 0.75 & 0.10 \\
\hline
\end{tabular}


Table 212 leads rest ECG parameters in PHPT patients (Group A and B) and controls. Results are presented as mean \pm 1 s.D.

\begin{tabular}{|c|c|c|}
\hline & \multicolumn{2}{|c|}{ PHPT } \\
\hline & Group A $(n=13)$ & Group B $(n=13)$ \\
\hline Heart rate (beats/min) & $72.4 \pm 9.4$ & $73.3 \pm 15.2$ \\
\hline$P(\mathrm{~ms})$ & $93.5 \pm 15.4$ & $103.8 \pm 24.0$ \\
\hline PR (ms) & $163.0 \pm 13.9$ & $158.1 \pm 15.2$ \\
\hline QRS (ms) & $71.6 \pm 16.1$ & $71.4 \pm 15.8$ \\
\hline QTc (ms) & $400.6 \pm 14.9$ & $399.0 \pm 14.7$ \\
\hline
\end{tabular}

\begin{tabular}{c}
\hline Controls $(n=26)$ \\
\hline $69.5 \pm 9.3$ \\
$90.3 \pm 17.9$ \\
$158.0 \pm 17.3$ \\
$76.1 \pm 11.2$ \\
$411.9 \pm 17.2 *, 0$ \\
\hline
\end{tabular}

QTc, QT corrected with Bazett formula, ${ }^{*} P \leq 0.05$ Group A vs controls and ${ }^{\circ} P \leq 0.05$ Group B vs controls.

any differences after 6 months compared to the baseline, in Group B.

Six months following PTx, mean values of QTc in Group A were significantly longer compared to mean values found at baseline $(400.6 \pm 14.9$ vs $410.1 \pm 7.0 \mathrm{~ms}$, $P=0.04)$, although within the normal range, and not significantly different compared to controls. Similar to baseline, a negative correlation was found after 6 months between QTc values and ionized calcium levels $(r=-0.60$, $P<0.05$ ), in the PHPT group (Fig. 3).

The prevalence of SVPBs in Group A was significantly reduced after PTx, as shown in Table 3. In particular, 6 months following surgery half of the patients who experienced SVPBs prior surgery did not have any SVPBs $(P=0.01)$. A more pronounced significant reduction of VPBs was noted; two-third of the patients with VPBs, 6 months following PTx had no VPBs $(P=0.04)$. We found no difference between the prevalence of arrhythmias in Group A following Ptx and controls (Table 3). The prevalence of both SVPBs and VPBs in Group B remained stable after 6 months.

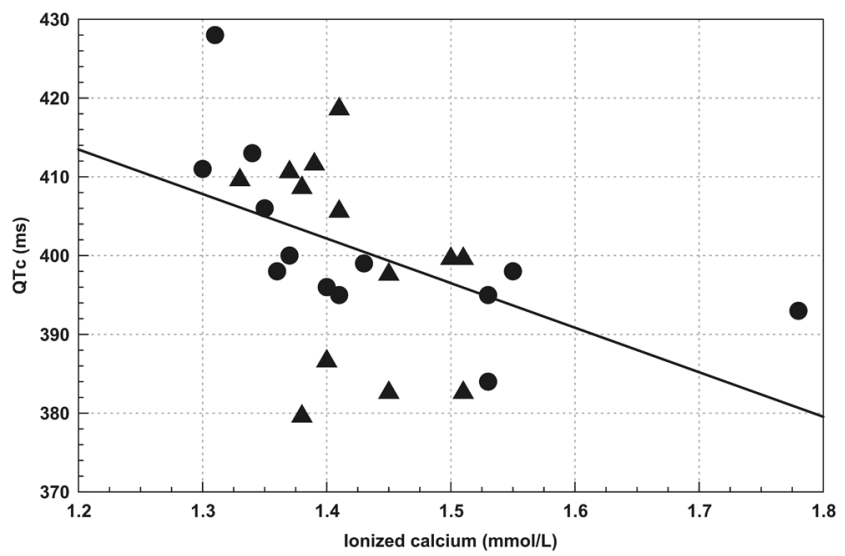

Figure 1

The baseline correlation between serum ionized calcium levels and QTc in the PHPT group. Closed circle symbols represent those who had PTX $(n=13)$ and closed triangle symbols represent those who did not have PTX $(n=13)$.

\section{Discussion}

This is the first randomized study showing a higher prevalence of arrhythmias, as detected by 24-h ECG monitoring, in PHPT patients compared to controls; most importantly, we demonstrated a significant reduction after PTx. This result confirms and extends our previous results obtained in a randomized study, which showed a positive effect of Ptx on the reduction of premature beats during exercise test in PHPT population (9).

It is of interest to note that the QTc interval in our population was within the normal range, even if shorter compared to controls, as has previously been reported by several studies also $(8,9,22)$. In this context, it is important to emphasize that a very large survey of more than 7000 persons, not affected by PHPT, showed that QT interval duration, in the lower values of the normal

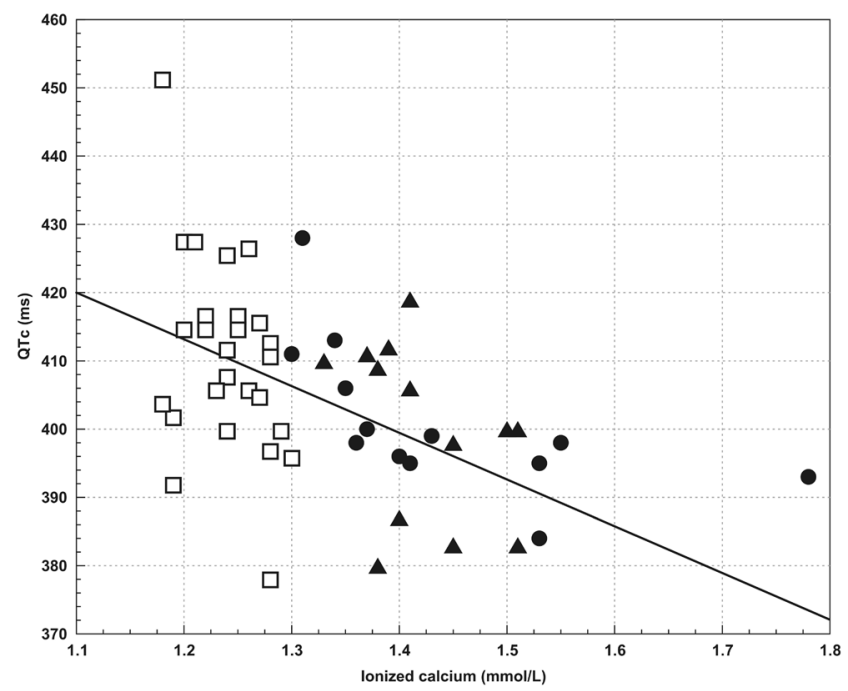

Figure 2

The correlation between serum ionized calcium levels and QTC in all samples studied.. Closed circle symbols represent those who had PTX $(n=13)$ and closed triangle symbols represent those who did not have PTX $(n=13)$; squared symbols represent controls $(n=26)$. 
Table 3 24-h heart rate and number of patients with arrhythmias in PHPT (Groups A and B at baseline and after 6 months) and controls.

\begin{tabular}{|c|c|c|}
\hline & \multicolumn{2}{|c|}{ PHPT Group A $(n=13)$} \\
\hline & Baseline & After 6 months \\
\hline 24-h heart rate (beats/min) & $74.8 \pm 8.1$ & $71.8 \pm 10.0$ \\
\hline Number of patients with SVPBs & 13 & $7 *$ \\
\hline SVPBs in couplets & 6 & 3 \\
\hline SVPBs in triplets & 4 & 2 \\
\hline Runs of more than 4 beats & 3 & 1 \\
\hline SVPBs higher than 76 & 4 & 1 \\
\hline Number of patients with VPBs & 9 & $3 *$ \\
\hline VPBs in couplets & 0 & 0 \\
\hline VPBs in triplets & 0 & 0 \\
\hline Runs of more than 4 beats & 1 & 0 \\
\hline
\end{tabular}

\begin{tabular}{|c|c|c|}
\hline \multicolumn{2}{|c|}{ PHPT Group B $(n=13)$} & \multirow[b]{2}{*}{ Controls $(n=26)$} \\
\hline Baseline & After 6 months & \\
\hline $71.3 \pm 7.6$ & $72.7 \pm 6.6$ & $73.1 \pm 7.9$ \\
\hline 12 & $13^{++}$ & $14^{\circ}, \S$ \\
\hline 8 & 6 & 7 \\
\hline 3 & 1 & $0^{\circ, \S}$ \\
\hline 4 & 3 & 2 \\
\hline 4 & 5 & $1^{\circ, \S}$ \\
\hline 9 & $11^{++}$ & $7^{\circ, \S}$ \\
\hline 3 & 2 & 2 \\
\hline 1 & 1 & 0 \\
\hline 1 & 1 & 0 \\
\hline
\end{tabular}

${ }^{*} P \leq 0.05$ Group A baseline vs Group A after 6 months; ${ }^{\circ} P \leq 0.05$ Group A baseline vs controls; ${ }^{\S} P \leq 0.05$ Group B baseline vs controls; ${ }^{++} P \leq 0.05$ Group A after 6 months vs Group B after 6 months.

SVPBs, supraventricular premature beats; VPBs, ventricular premature beats.

reference range, was associated with increased mortality risk (23). In PHPT patients, QTc correlated with ionized calcium levels; however, only $19 \%$ of the patients studied had calcium levels above $1 \mathrm{mg}$ - the upper normal range; thus, the population studied is representative of the current presentation of the disease in developed countries where mild hypercalcemia is very common $(24,25,26)$.

A short QTc might carry an increased risk of arrhythmia in the PHPT population; however, we should also keep in mind that arrhythmias are signs of possible coronary artery disease, even though in our study, we excluded patients with previous history of ischemic cardiac disease and other potential confounding factor such as diabetes. This indeed represents the strength of the investigation. Furthermore, the common cardiovascular risk factors

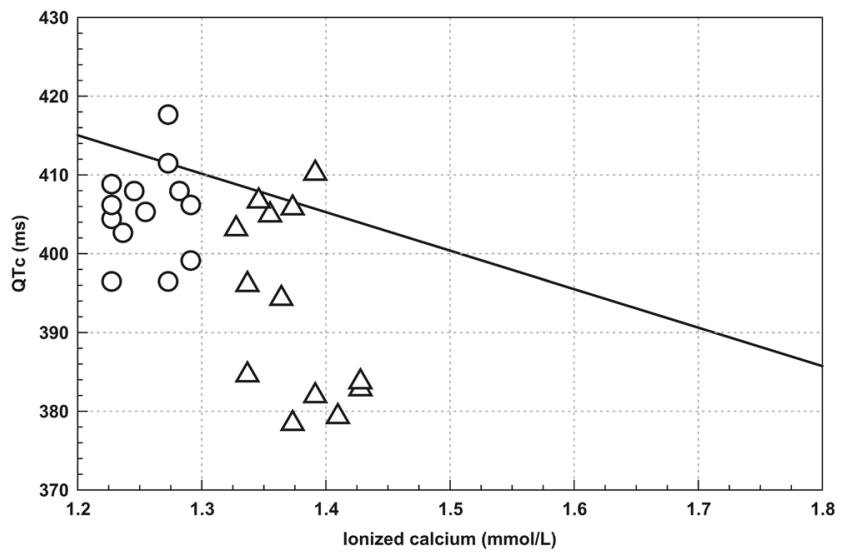

Figure 3

The correlation between ionized calcium levels and QTC in the PHPT group, after 6 months. Open circle symbols represent those who had PTX $(n=13)$ and open triangle symbols represent those who did not have PTX $(n=13)$. considered in our sample, such as hypertension and dyslipidemia, did not differ between PHPT patients and controls.

We cannot completely exclude that the burden of premature beats is also related to subclinical atherosclerosis. Indeed, in PHPT patients, a higher incidence of calcification has been reported in different arterial districts: both in the large vessels, such as the carotid and abdominal aortic $(27,28)$, and in small vessels such as the coronary arteries (29). However, the issue of coronary artery dysfunction in PHPT is still unresolved; some authors have demonstrated higher coronary calcifications in PHPT (30), while others have not (31), with conflicting results on the role of PTx in this context (32). Independently of this, premature ventricular beats are sign of electrical instability that surely should alerts physicians.

We did not find episode of atrial fibrillation or other life-threatening arrhythmias in our patients, but a significant higher prevalence of premature beats. This last observation could be considered of less clinical relevance; however, in the general population, a higher prevalence of premature atrial beats has been demonstrated to be associated with an increased incidence of ischemic stroke and composite cardiovascular events by several studies $(33,34,35,36,37)$. In a long-term follow-up study of 10 years, in the general population, more than 76 premature atrial beats per day have been shown to predict mortality with a sensitivity of $63.1 \%$ and a specificity of $63.5 \%(21)$.

We noted a significant reduction of premature beats and a prolongation of QTc, after Ptx in the presence of normocalcemia, which strengthens the role of even mild high serum calcium levels as a pro-arrhythmic factor. 
There is an important limit that we should consider when interpreting our results. We did not perform echocardiography. However, we excluded patients with a Sokolow-Lyon index higher than $3.5 \mathrm{mV}$, an ECG index threshold widely used as a measure for increased left ventricular (LV) hypertrophy (12). Indeed, it has been shown that an increased LV mass is associated with PHPT in some $(38,39)$, but not in all studies (7), and it has been shown, by a meta-analysis, to be significantly reduced after PTx (40). Another limit of the study concerns the possible bias related to the enrollment of the PHPT patients to our 'Metabolic Bone Disease Unit', a setting where patients with multiple complications are usually referred by other doctors. Thus, it might be possible that the PHPT population enrolled in our study is not representative of the PHPT population, which nowadays is diagnosed only by mild hypercalcemia occasionally discovered, without complications

In conclusion, on the basis of our data, a 24-h ECG monitoring test is advisable in patients with PHPT, in order to evaluate arrhythmic risk, even in patients with a mild serum calcium level elevation and QTc within the normal range. We demonstrated a curative role of PTx, with a significant reduction of premature beats 6 months following surgical intervention. The clinical implication of our study should lead to an increase in clinicians' awareness that a more accurate follow-up, with 24-h ECG monitoring, may allow early detection of arrhythmias in PHPT. It is also important to monitor those PHPT patients who do not undergo surgery, with a follow-up, which possibly includes a cardiological assessment.

Finally, our study was carried out in a relatively small group of patients with a short follow-up; however, if our results are confirmed in a larger sample with longer follow-up studies, an assessment of arrhythmic risk should become a topic to discuss in the agenda of the next "International Workshop" on the management of PHPT patients.

\section{Declaration of interest}

The authors declare that there is no conflict of interest that could be perceived as prejudicing the impartiality of this study.

\section{Funding}

This research did not receive any specific grant from any funding agency in the public, commercial or not-for-profit sector.

\section{References}

1 Minisola S, Pepe J, Piemonte S \& Cipriani C. The diagnosis and management of hypercalcaemia. BMJ $2015 \mathbf{3 5 0}$ h2723. (https://doi. org/10.1136/bmj.h2723)

2 Pepe J, Cipriani C, Sonato C, Raimo O, Biamonte F \& Minisola S. Cardiovascular manifestations of primary hyperparathyroidism: a narrative review. European Journal of Endocrinology 2017177 297-308 (https://doi.org/10.1530/EJE-17-0485)

3 Lind L \& Ljunghall S. Serum calcium and the ECG in patients with primary hyperparathyroidism. Journal of Electrocardiology 199427 99-103. (https://doi.org/10.1016/S0022-0736(05)80092-5)

4 Bilezikian JP, Khan AA, Potts JT Jr and on behalf of the Third International Workshop on the Management of Asymptomatic Primary Hyperthyroidism. Guidelines for the Management of Asymptomatic Primary Hyperparathyroidism: summary statement from the third international workshop. Journal of Clinical Endocrinology and Metabolism 200994 335-339. (https://doi. org/10.1210/jc.2008-1763)

5 Curione M, Letizia C, Amato S, Di Bona S, Di Fazio F, Minisola S, Mazzuoli F \& D'Erasmo E. Increased risk of cardiac death in primary hyperparathyroidism: what is a role of electrical instability? International Journal of Cardiology 2007121 200-202. (https://doi. org/10.1016/j.ijcard.2006.08.072)

6 Saikawa T, Tsumabuki S, Nakagawa M, Takakura T, Tamura M, Maeda T, Ito S \& Ito M. QT intervals as an index of high serum calcium in hypercalcemia. Clinical Cardiology 198811 75-78. (https://doi.org/10.1002/clc.4960110205)

7 Nilsson IL, Aberg J, Rastad J \& Lind L. Left ventricular systolic and diastolic function and exercise testing in primary hyperparathyroidism - effects of parathyroidectomy. Surgery 2000 128 895-902. (https://doi.org/10.1067/msy.2000.110240)

8 Pepe J, Curione M, Morelli S, Pepe J, Curione M, Morelli S, Colotto M, Varrenti M, Castro C, D'Angelo A et al. Arrhythmias in primary hyperparathyroidism evaluated by exercise test. European Journal of Clinical Investigation 201343 208-214. (https://doi. org/10.1111/eci.12038)

9 Pepe J, Curione M, Morelli S, Varrenti M, Cammarota C, Cilli M, Piemonte S, Cipriani C, Savoriti C, Raimo O et al. Parathyroidectomy eliminates arrhythmic risk in primary hyperparathyroidism, as evaluated by exercise test. European Journal of Endocrinology 2013169 255-261. (https://doi.org/10.1530/EJE-13-0293)

10 Walker MD, Rubin M \& Silverberg SJ. Nontraditional manifestations of primary hyperparathyroidism. Journal of Clinical Densitometry 2013 16 40-47. (https://doi.org/10.1016/j.jocd.2012.11.008)

11 Pepe J, Cipriani C, Pilotto R, De Lucia F, Castro C, Lenge L, Russo S, Guarnieri V, Scillitani A, Carnevale V et al. Sporadic and hereditary primary hyperparathyroidism. Journal of Endocrinological Investigation 201134 40-44.

12 Sokolow M \& Lyon TP. The ventricular complex in left ventricular hypertrophy as obtained by unipolar precordial and limb leads. American Heart Journal 194937 161-186. (https://doi. org/10.1016/0002-8703(49)90562-1)

13 Montomoli M, Gonnelli S, Giacchi M, Mattei R, Cuda C, Rossi S $\&$ Gennari C. Validation of a food frequency questionnaire for nutritional calcium intake assessment in Italian women. European Journal of Clinical Nutrition 200256 21-30. (https://doi.org/10.1038/ sj.ejcn.1601278)

14 Pepe J, Isidori AM, Falciano M, Iaiani G, Salotti A, Diacinti D, Fiacco Rd, Sbardella E, Cipriani C, Piemonte S et al. The combination of frax and aging male symptoms scale better identifies treated hiv males at risk for major fracture. Clinical Endocrinology $20127 \mathbf{7}$ 672-678. (https://doi.org/10.1111/j.1365-2265.2012.04452.x)

15 Paglia F, Dionisi S, De Geronimo S, Rosso R, Romagnoli E, Raejntroph N, Ragno A, Celi M, Pepe J, D'Erasmo E et al. Biomarkers 
of bone turnover after a short period of steroid therapy in elderly men. Clinical Chemistry 200147 1314-1316.

16 Caldwell G, Kellett HA, Gow SM, Beckett GJ, Sweeting VM, Seth J \& Toft AD. A new strategy for thyroid function testing. Lancet 19851 1117-1119. (https://doi.org/10.1016/S0140-6736(85)92429-8)

17 Pedrazzoni M, Girasole G, Bertoldo F, Bianchi G, Cepollaro C, Del Puente A, Giannini S, Gonnelli S, Maggio D, Marcocci C et al. Definition of a population-specific DXA reference standard in Italian women: the Densitometric Italian Normative Study (DINS). Osteoporosis International 200314 978-982. (https://doi.org/10.1007/s00198-003-1521-1)

18 Genant HK, Wu CY, van Kuijk C \& Nevitt MC. Vertebral fracture assessment using a semiquantitative technique. Journal of Bone Mineral Research 19939 1137-1148. (https://doi.org/10.1002/ jbmr.5650080915)

19 Cipriani C, Biamonte F, Costa Ag, Zhang C, Biondi P, Diacinti D, Pepe J, Piemonte S, Scillitani A, Minisola S et al. Prevalence of kidney stones and vertebral fractures in primary hyperparathyroidism using imaging technology. Journal of Clinical Endocrinology and Metabolism 2015100 1309-1315. (https://doi.org/10.1210/jc.2014-3708)

20 Bazzet HD. An analysis of the time relations of electrocardiograms. Heart 19207 353-370.

21 Lin CY, Lin YJ, Chen YY, Chang SL, Lo LW, Chao TF, Chung FP, $\mathrm{Hu}$ YF, Chong E, Cheng HM et al. Prognostic significance of premature atrial complexes burden in prediction of long-term outcome. Journal of American Heart Association 20154 e002192. (https://doi.org/10.1161/JAHA.115.002192)

22 Vázquez-Díaz O, Castillo-Martínez L, Orea-Tejeda A, OrozcoGutiérrez JJ, Asensio-Lafuente E, Reza-Albarrán A, Silva-Tinoco R \& Rebollar-González V. Reversible changes of electrocardiographic abnormalities after parathyroidectomy in patients with primary hyperparathyroidism. Cardiology Journal 200916 241-245.

23 Zhang Y, Post WS, Dalal D, Blasco-Colmenares E, Tomaselli GF \& Guallar E. QT-interval duration and mortality rate: results from the Third National Health and Nutrition Examination Survey. Archives of Internal Medicine 2011171 1727-1733. (https://doi.org/10.1001/ archinternmed.2011.433)

24 Minisola S, Pepe J, Scillitani A \& Cipriani C. Explaining geographical variation in the presentation of primary hyperparathyroidism. Lancet Diabetes Endocrinology 20164 641-643. (https://doi.org/10.1016/ S2213-8587(16)00076-0)

25 De Lucia F, Minisola S, Romagnoli E, Pepe J, Cipriani C, Scillitani A, Parikh N \& Rao DS. Effect of gender and geographic location on the expression of primary hyperparathyroidism. Journal of Endocrinological Investigation 201336 123-126. (https://doi. org $/ 10.3275 / 8455)$

26 Birgander M, Juul-Möller S, Bondeson AG, Bondeson L \& Rydberg E. Adrenergic and cardiac dysfunction in primary hyperparathyroidism Clinical Endocrinology 201276 189-195. (https://doi.org/10.1111/ j.1365-2265.2011.04169.x)

27 Nuzzo V, Tauchmanovà L, Fonderico F, Trotta R, Fittipaldi MR, Fontana D, Rossi R, Lombardi G, Trimarco B \& Lupoli G. Increased intima-media thickness of the carotid artery wall, normal blood pressure profile and normal left ventricular mass in subjects with primary hyperparathyroidism. European Journal of Endocrinology 2002 147 453-459. (https://doi.org/10.1530/eje.0.1470453)

28 Pepe J, Diacinti D, Fratini E, Nofroni I, D'Angelo A, Pilotto R, Savoriti C, Colangelo L, Raimo O, Cilli M et al. High prevalence of abdominal aortic calcification in patients with primary hyperparathyroidism as evaluated by Kauppila score. European Journal of Endocrinology 2016175 95-100. (https://doi.org/10.1530/EJE-151152)

29 Osto E, Fallo F, Pelizzo MR, Maddalozzo A, Sorgato N, Corbetti F, Montisci R, Famoso G, Bellu R, Lüscher TF et al. Coronary microvascular dysfunction induced by primary hyperparathyroidism is restored after parathyroidectomy. Circulation 2012126 1031-1039. (https://doi.org/10.1161/CIRCULATIONAHA.111.081307)

30 Marini C, Giusti M, Armonino R, Ghigliotti G, Bezante G, Vera L, Morbelli S, Pomposelli E, Massollo M, Gandolfo P et al. Reduced coronary flow reserve in patients with primary hyperparathyroidism: a study by G-SPECT myocardial perfusion imaging. European Journal of Nuclear Medicine and Molecular Imaging 201037 2256-2263. (https://doi.org/10.1007/s00259-010-1599-6)

31 Streeten EA, Munir K, Hines S, Mohamed A, Mangano C, Ryan KA $\&$ Post W. Coronary artery calcification in patients with primary hyperparathyroidism in comparison with control subjects from the multi-ethnic study of atherosclerosis. Endocrine Practice 200814 155-161. (https://doi.org/10.4158/EP.14.2.155)

32 Dural C, Okoh AK, Seicean A, Yigitbas H, Thomas G, Yazici P, Shoenhagen P, Doshi K, Halliburton S \& Berber E. A pilot study investigating the effect of parathyroidectomy on arterial stiffness and coronary artery calcification in patients with primary hyperparathyroidism. Surgery 2016159 218-224. (https://doi. org/10.1016/j.surg.2015.07.037)

33 Ofoma U, He F, Shaffer ML, Naccarelli GV \& Liao D. Premature cardiac contractions and risk of incident ischemic stroke. Journal of American Heart Association 20121 e002519. (https://doi.org/10.1161/ JAHA.112.002519)

34 Binici Z, Intzilakis T, Nielsen OW, Køber L \& Sajadieh A. Excessive supraventricular ectopic activity and increased risk of atrial fibrillation and stroke. Circulation 2010121 1904-1911. (https://doi. org/10.1161/CIRCULATIONAHA.109.874982)

35 Engström G, Hedblad B, Juul-Möller S, Tydén P \& Janzon L. Cardiac arrhythmias and stroke: increased risk in men with high frequency of atrial ectopic beats. Stroke 200031 2925-2929. (https://doi. org/10.1161/01.STR.31.12.2925)

36 Chong BH, Pong V, Lam KF, Liu S, Zuo ML, Lau YF, Lau CP, Tse HF \& Siu CW. Frequent premature atrial complexes predict new occurrence of atrial fibrillation and adverse cardiovascular events. Europace 2012 14 942-947. (https://doi.org/10.1093/europace/eur389)

37 Dewland TA, Vittinghoff E, Mandyam MC, Heckbert SR, Siscovick DS, Stein PK, Psaty BM, Sotoodehnia N, Gottdiener JS \& Marcus GM. Atrial ectopy as a predictor of incident atrial fibrillation: a cohort study. Annals of Internal Medicine 2013159 721-728. (https://doi. org/10.7326/0003-4819-159-11-201312030-00004)

38 Näppi S, Saha H, Virtanen V, Limnell V, Sand J, Salmi J \&, Pasternack A. Left ventricular structure and function in primary hyperparathyroidism before and after parathyroidectomy. Cardiology 200093 229-233. (https://doi.org/10.1159/000007031)

39 Piovesan A, Molineri N, Casasso F, Emmolo I, Ugliengo G, Cesario F \& Borretta G. Left ventricular hypertrophy in primary hyperparathyroidism. Effects of successful parathyroidectomy. Clinical Endocrinology 199950 321-328. (https://doi.org/10.1046/ j.1365-2265.1999.00651.x)

40 McMahon DJ, Carrelli A, Palmeri N, Zhang C, Di Tullio M, Silverberg SJ \& Walker MD. Effect of parathyroidectomy upon left ventricular mass in primary hyperparathyroidism: a meta-analysis. Journal of Clinical Endocrinology and Metabolism 2015100 4399-4407. (https://doi.org/10.1210/jc.2015-3202)
Received 12 November 2017

Revised version received 30 April 2018

Accepted 1 June 2018 